\title{
Baile Funk, missão civilizatória e UPP: cultura e segurança pública na cidade do Rio de Janeiro
}

Dentre as representações sobre o Brasil como nação moderna e miscigenada, certamente a música tem centralidade na produção das imagens e divulgação de um certo "espírito popular nacional". No entanto, tanto o conceito de popular como as compreensões cotidianas sobre nação, são (principalmente com o fim da escravidão) temas de disputa política nacional. Esta disputa não se resume as esferas partidárias e aos assuntos de Estado mas são matéria de trabalho de cientistas, viajantes, artistas, interessados na compreensão e conformação das representações sociais sobre a proximidade entre diferentes grupos étnico-raciais (Schwarcz,1997).

A forma como o controle das populações ocorre no Brasil pós Abolição tem nesta singularidade seu mito de origem, formidavelmente registrado por Gilberto Freyre em sua obra Casa Grande e Senzala, publicado no Brasil em 1933. A obra desperta o interesse de vários pesquisadores estrangeiros e compõe junto a outros movimentos culturais nacionais, um cenário de transformação definitiva das representações sobre o país. Era a definitiva alteração das visões que insistiam em um atraso civilizacional cuja explicação corrente era a "presença africana no país". Tradição e modernidade seguem como temas centrais para o pensamento social brasileiro considerando o legado da escravidão na formação da nação, na forma da experiência citadina de interação entre brancos e negros no país e sobretudo nas diferentes soluções para o problema do controle social das populações. 
Esta presença no espaço da zona rural (principalmente Nordeste brasileiro) e posteriormente nas cidades da região sudeste (principalmente Rio de Janeiro), era experimentada através da música, em momentos religiosos ou de festa. Manifestações como lundu, maxixe e mais contemporaneamente o samba, foram classificadas como "expressões chulas" em oposição à expressões europeias como a ópera italiana. A perseguição a musicalidade de matriz africana não é um fato novo no Brasil. Mesmo nas infindáveis discussões sobre o nascimento do samba e sua paternidade, não seria possível desconhecer que a prática de danças (incluindo aqui a capoeira) africanas quando exibidas em determinados espaços (quanto mais públicos, mais combatidos) foram alvo de perseguição antes de ocupar o lugar de maior signo da brasilidade.

Considerando a cidade do Rio de Janeiro como importante lócus de produção cultural nacional, o ensaio a ser apresentado pretende dar conta da complexidade do fenômeno funk na sua relação com o Estado, especificamente com os Órgãos de Segurança Pública nas primeiras décadas do século XXI.

\section{Favela e práticas culturais criminalizadas}

Em outubro de 1992, grupos de adolescentes vindos dos subúrbios, favelas da zona norte carioca e Baixada Fluminense, protagonizaram cenas de enfrentamento na praia do Arpoador. Estas cenas, transmitidas por canais de televisão, intensificaram uma sensação de medo, presente historicamente nas interações com moradores de favela na cidade do Rio de Janeiro. Não eram quaisquer moradores, não eram as "famílias suburbanas" que frequentavam as praias aos fins de semana que ocupavam as faixas de 
areia naquele dia. A partir do fato batizado como "Arrastão" ${ }^{1 "}$, estes jovens, vindos de favelas como Jacaré, Mangueira, da Baixada Fluminense ou de bairros do subúrbio, serão nomeados de forma distinta das demais hordas juvenis que circulavam pela cidade: serão classificados, nos meios de comunicação, pelos órgãos de segurança e pelos demais moradores da cidade como "funkeiros" (Silva, 2014,p.167).

As representações sobre jovens moradores de favela que frequentavam ou ouviam um tipo de música associados ao tráfico, tornaram-se dominantes nas mídias locais. O estigma que gestaria o emprego do termo "funkeiro" como categoria de classificação, gerou letras e posições dos próprios frequentadores de defesa do seu direito de ir aos bailes e de uma identidade que não poderia ser identificada como criminosa em função do lugar de moradia, cor ou adesão e determinada estética e música. A temática da favela como lugar de "pessoas honestas e trabalhadoras" foi parte de um importante momento no cenário musical nacional. Para este trabalho serão apresentadas algumas letras desta época: Rap do Silva, de Bob Rum, um artista da zona oeste carioca e Rap da Felicidade, gravado por Cidinho e Doca, dois funkeiros bastante populares no país, Endereço dos Bailes e Rap da Igualdade. Em Rap do Silva, interpretado por Bob Rum, lemos que:

“Todo mundo devia nessa história se ligar, Porque tem muito amigo que vai pro baile dançar... Esquecer os atritos, Deixar a briga pra lá $\mathrm{E}$ entender o sentido quando o DJ detonar. Era só mais um Silva que a

\footnotetext{
${ }^{1}$ Sobre as versões em relação ao evento, cabe apresentar a versão da Policia Militar: Os comandantes do $19^{\circ}$. E $23^{\circ}$. BPM (Batalhão da Policia Militar) são taxativos: os arrastões ocorridos anteontem nas praias da zona sul não tiveram o propósito de roubar os banhistas. Segundo eles, os participantes fazem parte dos mesmos grupos que frequentam os bailes funk do subúrbio da Zona Leste. O encontro das turmas rivais na areia provocou o tumulto e o pânico entre banhistas. Os incidentes ocorridos nas saídas das praias, explicam os oficiais, aconteceram devido ao número insuficiente de ônibus nos pontos finais.
} 
estrela não brilha, Ele era funkeiro Mas era pai de família, Era um domingo de sol, Ele saiu de manhã, Pra jogar seu futebol, Levou uma rosa pra irmã, Deu um beijo nas crianças, Prometeu não demorar, Falou pra sua esposa que ia vir pra almoçar, Era trabalhador, pegava o trem lotado, E a boa vizinhança era considerado, E todo mundo dizia que era um cara maneiro, Outros o criticavam porque ele era funkeiro...O funk não é modismo, É uma necessidade, É pra calar os gemidos que existem nessa cidade".

A letra foi selecionada por apresentar um tipo ideal médio. Um trabalhador, morador de áreas mais distantes e culturalmente estigmatizadas. Um cotidiano marcado pelo trabalho, família e adesão ao baile funk como forma de lazer. As relações sociais são apresentadas a partir da vizinhança, da família (esposa, filhos). Ser "mais um Silva" no Brasil significa não ter um nome de família marcado pela distinção, fazer parte de um contingente de anônimos que como ele, são Silvas e fazem uso de um trem lotado. Ser mais um Silva e ir ao baile significa portar-se dentro de uma ordem social. Na qual o lugar de cada um é assegurado e reconhecido. Apesar da adesão ao baile, a música demarca a adesão ao mundo do trabalho. O protagonista não está questionando o governo ou aliando-se a uma temática de protesto. Não da forma como o faz grupos como os Racionais Mcs em São Paulo. O que torna a produção carioca deste período um tema relevante de análise, são os lugares de fala. A condição de morador de favela é assumida e é a partir desta classificação que a reivindicação nos é apresentada nas letras. O direito ao baile não é apenas o direito à uma festa. Aqui ele adquire significado que transcende o entretenimento: é o direito de ir e vir no espaço urbano, de expor-se com roupas e tênis próprios para ocasião e acima de tudo, de fazer uso do tempo, fora do 
mundo do trabalho, marcado por humilhações cotidianas que começam nas formas de transporte (os trens lotados, as distâncias) as jornadas nem sempre remuneradas corretamente). A letra de Rap da Felicidade segue esta mesma temática:

“Eu só quero é ser feliz, andar tranquilamente na favela onde eu nasci, e poder me orgulhar, e ter a consciência que o pobre tem seu lugar. Minha cara autoridade eu já não sei o que fazer, com tanta violência eu tenho medo de viver, pois moro na favela e sou muito desrespeitado, a tristeza e alegria aqui caminham lado a lado, eu faço uma oração para uma santa protetora, mas sou interrompido a tiros de metralhadora, enquanto os ricos moram numa casa grande e bela, o pobre é humilhado, esculachado na favela, já não aguento mais esta onda de violência, só peço autoridade um pouco mais de competência/ diversão hoje em dia não podemos nem pensar, pois até lá no baile eles vêm nos humilhar, pessoas inocentes que não tem nada haver, estão perdendo hoje o seu direito de viver, nunca vi cartão postal que se destaque uma favela, só vejo paisagem muito linda e muito bela, quem vai pro exterior da favela sente saudade, o gringo vem aqui e não conhece a realidade, vai pra zona sul pra conhecer água de coco, e o pobre na favela vive passando sufoco., trocaram a presidência, uma nova esperança, sofri na tempestade agora eu quero a bonança, o povo tem a força, só precisa descobrir, se eles lá não fazem nada, faremos tudo daqui".

É possível inferir que o Rap da Felicidade é uma das letras mais conhecidas deste estilo no Brasil. O discurso sobre a favela como lugar de perigo e crime, adquire a partir dos 
Festivais de Rap cariocas, seu contra-discurso. Nenhuma letra demonstra tão bem este contra-discurso como Rap da Felicidade. O lugar aqui é reivindicado como direito de uso do espaço urbano: "e poder me orgulhar, e ter a consciência que o pobre tem seu lugar". Curiosamente "ter o seu lugar" parece indicar que não há a pretensão de saída do território. Talvez o objetivo seja dialogar com o medo difuso na sociedade externa à favela quando a periculosidade de seus moradores. O Estado é interpelado "minha cara autoridade" e percebemos que a violência altera as rotinas dos moradores.

Em "Endereço dos bailes" temos um formato bastante adotado no funk carioca e que será posteriormente adotado também em letras de funks classificados como proibidos. A nomeação de favelas da cidade nas quais circulariam os frequentadores. Se nestes momento as letras cantadas por duplas como Mc Leonardo e Mc Júnior, Cidinho e Doca entre outros, pede paz para o baile, no momento atual as letras versam sobre a relação entre facções e com a polícia:

No Rio tem mulata e futebol, Cerveja, chopp gelado, muita praia e muito sol, é..Tem muito samba, Fla-Flu no Maracanã, Mas também tem muito funk rolando até de manhã. Vamos juntar o mulão e botar o pé no baile $\mathrm{Dj}$.. ê ê ah! Peço paz para agitar, Eu agora vou falar o que você quer escutar, Ê ê ê ê, se liga que eu quero ver, o endereço dos bailes eu vou falar pra você. É que de sexta a domingo na Rocinha o morro enche de gatinha, que vem pro baile curtir, ouvindo charme, rap, melody ou montagem, é funk em cima, é funk embaixo, que eu não sei pra onde ir! O Vidigal também não fica de fora, final de semana rola um baile shock legal, a sexta-feira lá no Galo é, consagrada, a galera animada faz do baile um festival! Tem outro baile que a galera toda treme, é lá no baile 
do Leme lá no Morro do Chapéu, tem na Tijuca um baile que é sem bagunça A galera fica maluca lá no Morro do Borel Ê ê ê ah!

Outras letras como Rap da Igualdade apresentam conteúdo crítico na relação entre asfalto e favela, Estado e morador, justiça e percepção de injustiça. Lemos que "a injustiça vem do asfalto pra favela, há discriminação à vera, chegam em cartão postal, em outdoor a burguesia nos revela que o pobre na favela tem instinto marginal, e o meu povo quando desde pro trabalho pede a Deus que o defenda deste gente ilegal doutor, que nos maltrata e que finge não saber, que a guerra na favela é um problema social! Eu não sou marginal!".

O conteúdo de Rap da Igualdade é explicitamente crítico e adota uma perspectiva de classe ao nomear a oposição asfalto/favela e burguesia/moradores pobres. Além disto, a letra apresenta uma interpretação muito próxima daquela feita por estudiosos do tema favela à época em que este toma espaço nos grandes veículos de comunicação. A favela carioca tem sido estudada com regularidade nos últimos 30 anos e com certa intensidade na última década, o que possibilitou uma troca entre moradores, lideranças comunitárias e pesquisadores. Favelas como Rocinha e Maré construíram Centros de Memória, que contam em seu acervo com livros e produção acadêmica sobre o assunto. É possível inferir que esta relação também altera a percepção dos moradores sobre seu cotidiano e suas relações com o a cultura, o espaço urbano, o Estado, a polícia. Assim como no Rap da Felicidade, a demarcação moral é apresentada nesta passagem "eu não sou marginal". Outro elemento presente na construção desta oposição é o mundo do trabalho, caracterizado na passagem "e o meu povo quando desce pro trabalho, pede a Deus que o defenda". Esta associação entre funk e criminalidade foi exposta pelos Órgãos de Segurança 
Quando em 2008, o coronel Marcus Jardim, comandante do policiamento da capital, declarou em jornal de grande circulação que "iriam para dentro da bandidagem" e que "baile funk em favela é reunião de vagabundos", as representações sobre o freqüentador de baile funk como aliado ao tráfico de drogas, já eram parte do mapa cognitivo da interação entre favela e asfalto. Em declarações posteriores dissera que a Policia Militar era o melhor "inseticida social". Sua visão sobre bailes era "Baile funk em favela é reunião de vagabundos": Como comandante de um batalhão ou agora de uma área de comando, não tenho poder para proibir esses bailes, mas posso dificultar a sua realização ${ }^{2 \prime}$. E a proibição dos bailes, seria aceitável como parte do combate ao principal problema da cidade: a violência urbana. A lei 5.265 de autoria do ex-secretário Álvaro Lins, apresentava uma série de exigências para realização dos bailes. Suas observações se referiam à implementação do PAC, Plano do Aceleramento do Crescimento, que chegaria às favelas como o Complexo do Alemão, onde anos atrás teria ocorrido o assassinato de Tim Lopes, evento limite que instaurara uma percepção de que os bailes eram lugares de venda de drogas e práticas pornográficas (Silva, 2013, 2104).

A instauração das UPPS, a partir de 2008, na cidade do Rio de Janeiro, altera o discurso da guerra, presente na declaração feita pelo Comandante Marcus Jardim. Ao invés de "ir para cima da bandidagem" o lema a partir das UPPS é devolver os territórios aos moradores e a paz à cidade. Mesmo com um entusiasmo renovado nos potenciais da cidade, alguns problemas têm surgido. A tensão em relação a presença da

\footnotetext{
${ }^{2} \mathrm{O}$ coronel afirmou ainda que os eventos são utilizados pelos criminosos para a venda de drogas. Marcus Jardim já comandou os batalhões de Alcântara $\left(7^{\circ} \mathrm{BPM}\right)$, de Niterói (12 $\left.\mathrm{BPM}\right)$ e de Olaria (16 $\left.\mathrm{BPM}\right)$. Em todas as unidades, promoveu ações contra os bailes.
} 
polícia $^{3}$, ou do Exército, em áreas como o Complexo do Alemão e Rocinha, demonstra as dificuldades de administração de favelas bem mais populosas que o Morro Santa Marta. Neste quadro de equilíbrio instável novamente o baile funk é alvo de proibições por parte do Estado. Neste caso mais especificamente, a resolução 013 de 2007, que dá aos policiais (Comandante ou Delegado da Policia Civil), o direito de autorizar ou não a realização de bailes (Silva, 2014, p 173). Na resolução podemos ler4:

O Secretário de Estado e Segurança Pública no exercício de suas atribuições legais e consoante o que dispõe a CI 03/2006 considera a necessidade de uniformizar a atuação conjunta dos órgãos de administração pública e estadual na manutenção e preservação da ordem pública na realização de eventos artísticos, sociais e desportivos no Estado do Rio de Janeiro. Nesta resolução os órgãos públicos deverão ser informados previamente acerca da realização de eventos em locais que demandem o emprego de seus profissionais, seja para o exercício do policiamento ostensivo ou ainda para o exercício da polícia judiciária. Este conhecimento prévio possibilitaria a realização de ações planejadas, conjuntas ou isoladas e a provisão de recursos humanos (leio 013, SSP, Rio de Janeiro).

Mesmo com a revogação da lei em agosto de 2013, pelo governador Sérgio Cabral, a tensão entre policiais das Unidades de Polícia Pacificadora e moradores, já estava

\footnotetext{
${ }^{3}$ As denúncias de recebimento de "mesadas" no Morro da Fallet, em 2011, como em outras favelas de UPP, geraram desconfiança da população carioca em relação a ocupação das favelas.

${ }^{4}$ http://of.org.br/noticias-analises/resolucao-013-cultura-regulada-pela-seguranca-publica/ acessado em agosto de 2015.
}

RRASILIANA- Journal for Brazilian Studies. Vol. 4, n.2 (2016). ISSN 2245-4373. 
instaurada. E o controle do volume atingiria não apenas os bailes mas os eventos privados. A revogação de uma lei não significa a alteração na forma de atuação dos Comandos destas áreas, principalmente Rocinha e Complexo do Alemão. O governador teria declarado: "A resolução foi importante naquele momento em que elas começaram a ser pacificadas. Hoje é outro momento e a gente está extinguindo (O Secretário de Segurança) Beltrame e eu. Queremos construir algo novo, envolvendo Prefeitura e Corpo de Bombeiros, como em qualquer lugar da cidade".

Em artigo de 2014, sobre a proibição dos bailes, foram apresentadas algumas questões que desencadearam conflitos entre moradores e policiais. As exigências para realização de bailes em favelas pacificadas, geraram críticas por parte dos moradores porque alteravam a rotina de lazer das favelas e a economia local. A manutenção da paz pública foi usada como justificativa para aplicação de exigências, tais como obrigação de fazer o pedido com 20 dias de antecedência para realização do evento, e oito dias antes do evento para resposta da autoridade local. Além disto, a autoridade local do Estado, poderia criar novos critérios para realização de eventos em favelas, o que revela a arbitrariedade e a pouca margem de negociação com a sociedade civil. Determinações como: existência de câmeras e seguranças com detector de metal, inviabilizaram a realização de bailes que eram comuns em favelas antes das UPPS. A altura do som tornou-se foco de controle da polícia que em casos mais extremos, entrou em conflito com moradores que se recusavam a atender aos seus pedidos 5 . A atuação dos policiais foi principalmente a prisão por desacato, como no caso envolvendo o rapper Fiell, preso e espancado por policias da UPP, em uma festa que deveria acabar as duas da manhã no morro Santa Marta (Silva, 2014,p173). O discurso dos representantes do Estado a frente

\footnotetext{
${ }^{5} \mathrm{http}: / /$ www.anovademocracia.com.br/no-67/2905-moradores-de-favelas-denunciam-crimes-das-upps, http://oglobo.globo.com/rio/rapper-acusa-policiais-de-upp-de-agressao-3004044, ação dos policiais frustra moradores de favela.
}

RRASILIANA- Journal for Brazilian Studies. Vol. 4, n.2 (2016). ISSN 2245-4373. 
das Unidades de Polícia Pacificadora são fundamentais para compreensão de como tem operado a polícia na relação com os moradores. Mesmo com a revogação da resolução 013, a tensão em algumas áreas pacificadas torna o funk alvo de perseguição. Principalmente as letras que recebem o título de "proibidão".

A reportagem de julho de 2013, na revista Democracia Viva, apresenta as declarações dos responsáveis pelas UPPS quanto a realização de bailes funk: “eu sou contra" afirma o capitão Glauco, da Providência. "Todo baile funk tem envolvimento com o tráfico. Apesar de ser uma cultura popular a população ainda não está preparada para isso. No futuro quando estiverem conscientizados, escutando música clássica, música popular brasileira, conhecendo outros ritmos, outras culturas, a gente até pode autorizar, mas hoje não". A mesma associação é corroborada pela capitã Priscilla ${ }^{6}$, que esteve a frente do Santa Marta, uma das primeiras favelas a receber a UPP no Rio de Janeiro, "para os trabalhadores, para a comunidade, ter um baile funk aqui hoje, significa que a polícia perdeu. É o simbolismo. Vai ter um dia? Vai. Mas não agora". Uma outra forma de legislar sobre o baile, foi adotada na Rocinha pelo coronel Renê Alonso: "não estou aqui para proibir o que é legal. Agora, os serviços têm normas a seguir. Se o baile vai ser realizado é preciso ter autorização da prefeitura e dos órgãos competentes. Se isto é feito, meu papel é dar segurança para a realização do baile". Sua declaração impõe a autorização dos órgãos competentes como condição para realização dos bailes. Submete a população ao gosto musical dos gestores públicos (Silva, 2014, p.173).

\footnotetext{
${ }^{6} \mathrm{http}: / /$ noticias.r7.com/rio-de-janeiro/noticias/primeira-comandante-de-upp-major-priscilla-ganha-premio-degoverno-dos-eua-pela-coragem-20120306.html. Capitã recebe prêmio "Mulheres de Coragem" dos Estados Unidos, a frente da primeira favela com UPP. A mídia internacional acompanha a ocupação do Santa Marta desde o início, sendo esta a UPP modelo da cidade do Rio de Janeiro.
} 
No discurso dos gestores da Segurança Pública no Rio de Janeiro, nas últimas décadas, o controle de população passa efetivamente pelo controle dos espaços de favela. O incremento do tráfico de drogas e armas, intensificou na década de 90, a associação entre moradores e criminalidade, tão presentes nas manchetes e exemplarmente visíveis no caso do Arrastão de 1992 no Arpoador. A localização desta periculosidade na juventude, não difere de conjunturas de outros países como França (o banlieue) ou dos guetos americanos habitados por negros e latinos. Metodologicamente, o baile funk torna possível a observação deste espaço de conflitos, dos discursos que pretendem o exercício de uma missão civilizatória na relação com os moradores. "Livrando-os" do gosto pelo funk e como disse o capitão Glauco, possibilitando que ouçam "música clássica". Se como declarou a capitã Priscilla, a frente do Santa Marta, em 2012, "ter o baile funk significa que a polícia perdeu, é um simbolismo", é provável que exista uma visão compartilhada pelos órgãos de segurança: o baile permanece ingovernável. A questão não são as letras erotizadas e equipes de som como a Furacão 2000 que tocam em grandes casas da cidade como a Riosampa. A proibição recai sobre os bailes de favela, organizados pela comunidade e com letras nem sempre conhecidas pelo grande público, que tornam esta prática cultural absolutamente indesejável para manutenção da ordem nos territórios de favela.

\section{Letras proibidas: pulsão para além da favela}

A tecnologia que possibilita o desenvolvimento do universo de mercadorias relacionadas ao funk passa distante das grandes gravadoras e das formas tradicionais de distribuição musical nos mercados globais atuais. Se é possível falar de um "espírito", da ânima do mundo funk nos anos 2000, seria possível defini-lo como uma experiência 
urbana tecnológica fundada em ritmos africanos, uma atualização de tambores, associada a centralidade do corpo em espaços sociais como bailes e shows. Este argumento tem como objetivo enfatizar o caráter interacional do fenômeno. Com o avanço de tecnologias de reprodução e barateamento dos preços para aquisição destes equipamentos, o funk adquire uma característica singular no mundo da música: a possibilidade de recorte e recomposição das letras, formando um tipo de colagem na qual a noção de autoria torna-se objeto de problematização (Silva, 2014, p.214).

Como parte destas experiências, a circulação e a distribuição das músicas está fora do controle de gravadoras tradicionais. Os bailes são momentos centrais do aparecimento de novas composições e após certos horários, da execução das letras consideradas "proibidas". Algumas destas são encomendadas por traficantes e em alguns casos, mesmo contrariados com a temática, os compositores acabam por executálas. São relações complexas que envolvem pagamentos por trabalhos realizados, percepção dos problemas gerados pela popularização de certas versões e em alguns casos, prisões. O Rap das Armas ${ }^{7}$ exemplifica as situações com a polícia e a recriação de versões consideradas "proibidas". Gravada em 1995 por MC Júnior e MC Leonardo, a letra faz a nomeação das armas existentes na favela. Alcançou reconhecimento á época. Sua introdução imitava uma rajada de metralhadora:

O meu Brasil é um país tropical, a terra do funk, a terra do carnaval, o meu Rio de Janeiro é um cartão postal, Mas eu vou falar de um problema nacional,

\footnotetext{
${ }^{7}$ http://4.bp.blogspot.com/_SAEAvnIotIg/S57QOhVd3DI/AAAAAAAAGO4/NKQj7Y10nfs/s1600-
} h/extra $1+\mathrm{c} \% \mathrm{C} 3 \%$ B3pia.jpg - o êxito de Rap das Armas torna-se mundial após o filme Tropa de Elite. 
parapapapapapapapa

parapapapapapapapa

paparapaparapapara clak bumm

parapapapapapapapa

Metralhadora AR-15 e muito oitão A Intratek com disposição, Vem a super 12 de repetição, 45 que um pistolão, FMK3, m-16, A pisto UZI, eu vou dizer para vocês, Que tem 765, 762, e o fuzil dá de 2 em 2, Nesse país todo mundo sabe falar, Que favela é perigosa, lugar ruim de se morar, mas ela é muito criticada por toda a sociedade, Mas existe violência em todo canto da cidade, Por falta de ensino falta de informação, pessoas compram armas, cartuchos de munição, mas se metendo em qualquer briga ou em qualquer confusão se sentindo, protegidas com a arma na mão, vem pistola glock, a HK, vem a intratek Granada pra detonar, vem a caça-andróide e a famosa escopeta, vem a pistola magnum, a Uru e a Beretta, colt 45, um tiro só arrebenta, e um fuzil automático com um pente de 90, estamos com um problema que é a realidade, e é por isso que eu peço paz, justiça e liberdade, Eu sou o MC Júnior, eu sou MC Leonardo, Voltaremos com certeza pra deixar outro recado Para todas as galeras que acabaram de escutar Diga não a violência e deixe a paz reinar.

Em uma versão posterior, Cidinho e Doca alteram a letra, mantendo a base:

Morro do Dendê é ruim de invadir, Nois, com os Alemão, vamo se diverti, Porque no Dendê eu vo dizer como é que é, Aqui não tem mole 
nem pra DRE, Pra subir aqui no morro até a BOPE treme, Não tem mole pro exército, civil nem pra PM, Eu dou o maior conceito para os amigos meus, Mais Morro do Dendê também é terra de Deus, Fé em Deus DJ , Vamu lá

Parapapapapapapapapa

Parapapapapapapapapa

Paparapaparapapara clack bum

Parapapapapapapapapa

Vem um de AR15 e outro de 12 na mão, Vem mais um de pistola e outro com 3 oitão, Um vai de URU na frente escoltando o camburão, Tem mais dois na retaguarda mas tão de Glock na mão, Amigos que eu não esqueço nem deixo pra depois, Lá vem dois irmãozinho de 762 É que eles são bandido ruim e ninguém trabalha, De AK47 e na outra mão a metralha, Esse rap é maneiro eu digo pra vocês, Quem é aqueles cara de M16, A vizinhança dessa massa já diz que não agüenta, Nas entradas da favela já tem ponto 50, E se tu toma um pá, será que você grita, Seja de ponto 50 ou então de ponto 30, Mas se for Alemão eu não deixo pra amanhã, Acabo com o safado dou-lhe um tiro de Pazã, Porque esses Alemão são tudo safado, Vem de garrucha velha dá dois tiro e sai voado, E se não for de revólver eu quebro na porrada $\mathrm{E}$ finalizo o rap detonando de granada (letra sem autoria reconhecida).

Esta versão renderia a dupla Júnior e Leonardo um convite para depor em delegacia já que a letra foi classificada como "apologia ao crime". Os irmãos foram liberados mas a 
letra permanece ainda como um dos primeiros e mais conhecidos funks proibidos da cidade do Rio de Janeiro.

Em dois registros para o cinema, a letra foi utilizada. Primeiramente por Kátia Lund e João Moreira Sales no documentário "Notícias de uma Guerra Particular" de 1999. O documentário apresenta um quadro geral sobre o enfretamento entre a polícia e os traficantes, daí seu título. Ao entrevistar moradores, traficantes, líderes comunitários, adolescentes presos, policiais, delegados. As narrativas têm um tom pessimista sobre a guerra ás drogas e sobre a favela. As condições carcerárias, os pátios lotados de adolescentes, todos negros, presos, a sofisticação do armamento e o questionamento sobre uma ação policial não seletiva, fazem deste documentário um documento histórico para compreender o Rio de Janeiro atual. Quando o filme Tropa de Elite de José Padilha foi lançado em 2007, sua abertura foi marcada pelo Rap das Armas na execução original de MC Júnior e MC Leonardo. O filme, mesmo sofrendo com o vazamento de uma cópia antes de sua estreia, teve um êxito singular para um filme nacional. Além disto, sua produção foi divulgada como o título "Elite Squad" nos Estados Unidos, elevando a letra da dupla à condição de uma das letras mais executadas em países como França, Bélgica, Israel, Suécia.

A temática adotada por duplas como Cidinho e Doca foi intensificada em letras que abordam o enfrentamento entre facções e com a polícia. Em letras posteriores, algumas cantadas por Mcs bastante populares, serão narradas situações cotidianas, decisões dentro das facções em relação aos inimigos ou aqueles compreendidos como "traidores", formas de comemoração, lembrança de parceiros mortos, cenas de crime, enfrentamentos com policiais e outras facções, cotidiano carcerário, entre outros temas,

\footnotetext{
${ }^{8} \mathrm{https}: / /$ www.youtube.com/watch?v=EAMIhC0klRo, íntegra do documentário.
} 
tendo a favela como tônica constante dos discursos. Em "Eu queria um G3"”, de autoria não facilmente reconhecida, lemos que: “ eu queria um G3 de vários pentes, pra botar a chapa quente e os X9 pra correr, lá no Engenho Novo é nóis que manda, nosso bonde é severo, vai lá que vocês vão ver". Aqui a letra faz referência à uma arma de grosso calibre, para enfrentamento de supostos informantes da polícia, em um território de domínio estabelecido. Sobre a autoria, estas letras são feitas em uma quantidade e velocidade inigualáveis. Implodem a noção de autoria na arte tal como estabelecida pela indústria para fins de arrecadação. Algumas delas sequer são gravadas em mídias convencionais. Alguns dos vídeos apresentam montagens de imagens dos enfretamentos e fotos de armas, carros e dos próprios frequentadores de bailes e Mcs. A letra acima é uma versão de Casinha Branca ${ }^{10}$, gravada em 1979, que ironicamente dizia "eu queria ter na vida simplesmente, um lugar de mato verde, pra plantar e pra colher, ter uma casinha branca de varanda, um quintal e uma janela, para ver o sol nascer".

Na próxima letra a nomeação da facção CV (Comando Vermelho) e de seus chefes, alguns deles, personagens presentes nos principais jornais da cidade. Como FB (Fabiano Atanázio) citado nesta composição, Bonde do Trem Bala: "sai da frente alemão, que o bonde vai passar, é o Complexo da Penha, FB, MK, vermelhão na veia, família Cruzeiro e Chatuba, estalou os fogos, morador sai da rua, blindado chega atirando não quer saber quem vai acertar". O termo "alemão" é empregado como sinônimo de inimigo. A referência à cor vermelha é muito comum em favelas sob domínio do Comando Vermelho. As áreas nomeadas (Penha, Cruzeiro e Chatuba) vivem sob o impacto da ação das facções. Mesmo com a entrada das Upps no Rio, o tráfico

\footnotetext{
${ }^{9} \mathrm{https}: / /$ www.youtube.com/watch?v=R5DfH10tDrM

${ }^{10}$ http://www.dicionariompb.com.br/joran/dados-artisticos, Dicionário Cravo Albin da Música Popular Brasileira, acessado em 16 de agosto de 2015
}

RRASILIANA- Journal for Brazilian Studies. Vol. 4, n.2 (2016). ISSN 2245-4373. 
permanece atuando e em certos territórios e existem enfrentamentos constantes entre policiais e moradores como no Complexo do Alemão ${ }^{11}$, zona norte do Rio de Janeiro.

Em Vida Bandida, Mc Smith descreve o cotidiano de um integrante destas facções: "a grossura do cordão, está causando um zum zum zum, mas é várias mulheres, vários fuzis a sua disposição, o batalhão da área, comendo na sua mão, nossa vida é bandida e nosso jogo é bruto, hoje seremos festa, amanhã seremos luto". Na mesma direção mas acrescentando a lógica da guerra, Mc Orelha canta "na Faixa de Gaza é só homem bomba, na guerra é tudo ou nada, várias titânio no pente e colete a prova de bala, perfume importado, pistola no coldre, mulher, ouro e poder, lutando que se conquista, nós não precisa de crédito, nós paga tudo à vista". Nestas duas letras a sociedade de consumo e os bens consumidos são nomeados como parte da conquista e da distinção local, o que na fala de muitos, alia-se a conquista de mulheres e respeito. A lógica da guerra é afirmada no pertencimento faccional e o elemento agonístico deste enfrentamento é a reflexão contínua sobre a morte, presente em muitas letras de rap e funk.

O processo de implantação das Unidades de Polícia Pacificadora também tornouse temática das letras de funk proibido. Muitas destas, narrando como será a volta das facções, outras narrando a alteração das rotinas, com a proibição dos bailes como em "Não entra aqui UPP" cantada por MC Tovi "Dentro das favelas, morador vive legal, com muita humildade, mas temos potencial, estamos unidos, canta aí comigo, o baile tá cheio e tá legal, eu tô revoltado com Sérgio Cabral, sem o baile aqui não vai ficar legal, mas pra ficar tranquilo, eu já sei o que vou fazer, o jeito é, não entrar aqui a UPP, o jeito é, não entrar aqui a UPP, se você quer saber o que vai acontecer, primeiro vocês entram,

\footnotetext{
${ }^{11}$ http://www.armazemdedados.rio.rj.gov.br/arquivos/1314_bairros\%20-\%202004.JPG bairros da cidade do Rio de Janeiro.
}

RRASILIANA- Journal for Brazilian Studies. Vol. 4, n.2 (2016). ISSN 2245-4373. 
depois vou te dizer". Na letra "Upp é o $c^{* * * * " ~ n o v a m e n t e ~ o ~ g o v e r n a d o r ~ e ́ ~ c i t a d o . ~ E ~}$ também o prefeito da cidade do Rio de Janeiro, Eduardo Paes:

“Aqui no morro é tudo nosso, É nosso bonde não o deles, UPP é o caralho, é bala neles, é bala neles, Valeu rapaziada da Providência, alô rapaziada do Santa Marta, alô rapaziada do Borel, alô rapaziada do Tabajara, nós vai voltar pra casa...vou convocá a rapaziada, vou convocá a rapaziada, UPP é o caralho, nós vai voltar pra casa, é bala neles, é bala neles, preparados pra dar tiro....nós vai voltar pra casa, unh aceita, nós fecha a Linha Amarela, a Vermelha e a Brasil, com nós não há quem possa, a favela é nossa, a nossa guerra vai ter final feliz, aguardem a volta vai ser triste ${ }^{12} \ldots$ acabou a paz, é pau no $\mathrm{c}^{*}$ do Cabral e bala no Eduardo Paes".

Um dos eventos mais emblemáticos da relação entre a produção de letras consideradas "proibidas" e os órgãos de segurança pública foi a prisão de vários Mcs após um show em que teriam feito apologia ao crime. Uma das edições do jornal O Globo, mostra Mc Smtih, Mc Frank. Mc Ticão e Mc Max, moradores do Complexo do Alemão e Penha, presos em uma delegacia e rimando para suas famílias. Na sequencia, a cena da delegada Helen Sardenberg, titular da delegacia de repressão aos crimes de informática, citando os artigos em que foram enquadrados, gera certa perplexidade. Em resumo, sua visão sobre a atitude dos músicos: "o vídeo feito por eles no aniversário do FB teve

\footnotetext{
${ }^{12}$ Algumas das versões : http://www.youtube.com/watch?v=7djUE9S27ZE, (Dj Gordinho), http://www.youtube.com/watch?v=zfdYvWX6LOo\&feature=endscreen\&NR=1 (Dj Billy), http://www.youtube.com/watch? $\mathrm{v}=$ UndNFtNDS1g\&feature=related montagem Complexo e Rocinha unidos contra UPP
} 
rapidamente mais de 400 mil acessos então isto demonstra a força que estes Mcs têm frente a nova juventude e principalmente a problemática social do Rio de Janeiro no que diz respeito ao tráfico de drogas".

As expressões faciais da delegada ${ }^{13}$ chamam atenção pela ênfase na tentativa de demonstração da periculosidade dos Mcs. Eles, ao contrário, expressam uma ironia crítica quando a prisão e as razões alegadas pela polícia. Questionam o fato de que ficaram em celas com pessoas que já mataram e roubaram, considerando sua prisão, desnecessária. Para Helen Sardenberg, eles usam o tráfico como forma de trampolim para suas carreiras (vale observar que este caminho raramente é feito por algum artista de funk). Durante a filmagem, os Mcs falam que se graças ao Estado o tráfico não está mais presente, é o momento para mostrar que "o Complexo não é só violência". Atrás das grades iniciam uma letra que fala do dia de sua prisão "o mãe não chore não, em breve eu tô de volta no Complexo do Alemão" ao final, mandam um abraço para Rede Globo e se despedem, citando os nomes de cada um. Em uma de suas falas, Helen Sardenberg afirma que isto é legal, e este é o "permitidão" em oposição ao funk proibido. Por ser feita para mãe dos Mcs, a letra estaria dentro de legalidade. Durante sua prisão, os Mcs ainda puderam fazer um show na carceragem com a presença de outros presos, cantando letras da época dos Raps que pediam por mais paz no baile.

\section{Baile funk: uma prática cultural indisciplinável?}

A conclusão deste artigo, após o desgaste das Upps junto a opinião pública, após casos como o sumiço do pedreiro Amarildo na Rocinha e a morte recente de uma criança de apenas dez anos no Complexo do Alemão, permanece ainda em aberto e com a mesma

\footnotetext{
${ }^{13}$ https://www.youtube.com/watch?v=iFtVJRXMmCQ\&feature=youtu.be prisão dos Mcs e falas da delegada H.
} Sardenberg. 
questão desenvolvida em artigo anterior (Silva, 2014). O que representa o baile para o Estado e especificamente as letras proibidas? Na primeira versão do estudo sobre os bailes e sua proibição, o termo empregado na conclusão foi "ingovernável". Nesta versão, a ideia permanece, mas soma-se a esta, o conceito de "indisciplina" como contraponto da ordem urbana que se busca estabelecer na formatação da cidade para os grandes eventos. Compreender a proibição dos bailes funk em favelas cariocas não constitui tarefa fácil. A hipótese de exercício de violência simbólica ${ }^{14}$, como desenvolvido por Bourdieu, poderia ser aceita. Nas falas do Capitão Glauco e da Capitã Priscilla, nas falas de comandantes que expressam seu gosto por outras músicas e na fala da delegada Helen Sardenberg, encontramos elementos que reforçam a posição do Estado em relação ao tipo de música que toca na favela. Mas este exercício de violência simbólica é acompanhado do exercício da violência física, empregada nas ações policiais contra os freqüentadores de bailes. É útil ao argumento, lembrar que os bailes de asfalto ocorrem normalmente sem intervenção policial. Portanto, o problema poderia ser explicado pelos "efeitos" conhecidos das letras em territórios de favela, que como declara Helen Sardenberg, "incitam os jovens contra a polícia" (Silva, 2014, p.176). Neste quadro, o cotidiano da favela entre na pauta da cidade e do país, em virtude dos grandes eventos e parte do funk produzido na cidade, representa o espaço “ingovernável" (Foucault, 1987) na relação entre favela e Estado, dentro de uma "nova" ordem a ser instituída.

\footnotetext{
${ }^{14}$ É enquanto instrumentos estruturados e estruturantes de comunicação e de conhecimento que os 'sistemas simbólicos' cumprem a sua função política de instrumentos de imposição ou de legitimação de dominação, que contribuem para assegurar a dominação de uma classe sobre outra (violência simbólica) dando o reforço de sua própria força e contribuindo assim, segundo a expressão de Weber, para a 'domesticação dos dominados'. Portanto, conduzir esta luta, quer diretamente nos conflitos simbólicos da vida cotidiana, quer por procuração, por meio da luta travada por especialistas da produção simbólica (produtores a tempo inteiro) e na qual está em jogo o monopólio da violência simbólica legítima (cf. Weber), quer dizer, do poder de impor - e mesmo de inculcar - instrumentos de conhecimento e de expressão (taxionomias) arbitrários - embora ignorados como tal - da realidade social (Bourdieu, 1989, p. 11).
}

RRASILIANA- Journal for Brazilian Studies. Vol. 4, n.2 (2016). ISSN 2245-4373. 
As letras proibidas (e parte das letras de funk) não apresentam em sua composição. elementos de melancolia e lirismo, presentes no samba e mesmo na bossa nova. Não possibilitam representações sobre integração social ou harmonia racial. Suas letras, quando em ataque a polícia, não apresentam nenhuma possibilidade de pacto ou negociação. A violência expressa nas letras, sobre as formas de humilhação, intimidação e execução do inimigo impossibilitam qualquer aplicação de uma tecnologia de docilização dos corpos por parte do Estado. Muitas letras disponibilizadas atualmente atacam frontalmente não só as UPPs como o prefeito Eduardo Paes, o governo Sérgio Cabral e até mesmo a presidenta Dilma Roussef (Silva, 2014,p.176).

Sobre o combate ao funk, importa lembrar que no discurso feito pelo Estado, a presença do termo "missão civilizatória" é um indicativo do tipo de controle objetivado com a instauração das UPPS. Nas representações sobre o funkeiro, mais do que uma linguagem comum ou adesão a um tipo de música é determinante o reconhecimento de sua ligação com determinados territórios da cidade. O funk como música (letra e signo) demarca esta região moral onde algumas ações são permitidas e outras podem ser severamente punidas. A retomada do território, principal objetivo desta política, só será possível a partir da legitimação das forças policiais, que garantam para fora da favela uma sensação amplificada de confiança em uma instituição desacreditada junto a sociedade civil. E para dentro da favela, prometam a devolução de uma rotina tranqüila aos seus moradores. Tanto os moradores das favelas pacificadas como a Polícia Militar do Rio de Janeiro padecem de estigmas. Os primeiros, associados a uma condição de baixa cultura, maus pagadores de impostos, pouco educados. Os policiais militares vistos como corruptos, abusivos e pouco eficazes no exercício de sua função (idem).

Em entrevistas realizadas no ano de 2013, foi possível perceber que a geração de moradores, com idades entre 14 e 30 anos, apresentava um grau maior de desconfiança 
em relação ao pacto proposto pelas UPPS. Cabe lembrar que as letras de funk também questionam o lugar do morador na cidade e descrevem com detalhes os abusos policiais. Por esta razão são documentos tão valiosos à pesquisa sociológica.

As prisões por desacato, em favelas de UPP exemplificam o dilema da construção democrática em territórios de favela versus uso de violência sobre um território que o Estado percebe como "ingovernável". O baile é o espaço mais visível do acirramento dos conflitos durante o processo de legitimação das UPPS. A justificativa da proibição de realização das festas por alegação de associação entre baile e tráfico não se sustenta. Em trabalho de campo, eram comuns os relatos de comandantes que diziam "faça um forró, um pagode, porque funk eu não gosto e não vou liberar". O que é combatido pelos órgãos de Segurança Pública não é o funk como entretenimento pois este continua a ser consumido nas mais diversas formas de mídia, festas de Ano Novo em Copacabana, reuniões familiares em salões de festa. O que é combatido é o funk como exercício de sociabilidade na favela, organizado pela comunidade e com letras que se disseminam como um "enxame". O registro feito cotidianamente por estes artistas integra um circuito urbano de cultura que se torna global, principalmente com o uso de tecnologias de gravação e divulgação via web. A revogação da autoria, as versões, a temporalidade, a descrição e divulgação simultâneas do baile, são alguns dos elementos que dificultam o controle das letras "proibidas" pelo Estado.

\section{Bibliografia}

Cabral, S. As escolas de samba do Rio de Janeiro. Rio de Janeiro, PLANRIO/Jorge Zahar, Ed. 1996 
Cechetto, F. Violência e estilos de masculinidade. In; Cechetto, Fátima. Violência, Cultura e Poder. Editora FGV, Rio de Janeiro, 2004, 245p.

Dayrell, J. O rap e o funk na socialização da juventude, In: Educação e Pesquisa, São Paulo, v 28, n 1, p 117-136, 2002.

Essinger, S. Batidão. Uma história do funk. Rio de Janeiro, Record, 2005.

Facina Adriana, Lopes, Adriana. Cidade do Funk, expressão da diáspora negra nas favelas cariocas, VI Encontro de Estudos Multidisciplinares em Cultura, Salvador, Bahia, 2010.

Foucault, M. Microfísica do Poder. Rio de Janeiro, Graal, 1976.

Giumbelli E. Valladão J. Naves, S. Cambraia (organização). Leituras sobre música popular: reflexões sobre sonoridades e cultura. Rio de Janeiro: 7 Letras, 2008.

Goffman, E. Estigma. Notas sobre a manipulação da identidade deteriorada. Rio de Janeiro: LTC, 1988.

Herschmann, M. Lapa, cidade da música: desafios e perspectivas para o crescimento do Rio de Janeiro e da indústria da música independente nacional. Rio de Janeiro: Mauad X, 2007. . O funk e o hip-hop invadem a cena. Editora da UFRJ, 2000, Rio de Janeiro

Kant de Lima, R. A polícia da cidade do Rio de Janeiro, seus avanços e paradoxos. Rio de Janeiro, Forense, 1995.

Lahire, B. Indivíduo e mistura de gêneros: dissonâncias culturais e distinção de si. Dados [online]. 2007, vol.50, n.4 [cited 2009-11-03], pp. 795-825 .

Leal, Sérgio José de Machado. Acorda hip-hop!: Despertando um movimento em transformação. Rio de Janeiro: Aeroplano, 2007.

Ledds, A. e Ledds, E. A sociologia do Brasil Urbano: Sociologia e Antropologia. Rio de Janeiro, Ed.Zahar, 1978. 
Lefevbre, H. O direito à cidade. Centauro, 2008

Machado da Silva, L. A. Qual é a das UPPS. Observatório das Metrópoles, março, 2010.

L. A. "Violência e sociabilidade: tendências da atual conjuntura urbana no Brasil. In Queiroz Ribeiro, L. C. e Santos, Jr. O. A. (orgs.) Globalização e Reforma urbana. Rio de Janeiro, Civilização Brasileira, 1994.

Misse, M. "Cinco teses equivocadas sobre a criminalidade urbana no Brasil: uma abordagem crítica acompanhada de sugestões para uma agenda de pesquisa, Série Estudos, n. 91, Rio de Janeiro, 1995 a.

Soares, L. S. , Santo Sé, j. T. , Rodrigues, j. , a. S e Piquet Carneiro. Violência e Polícia no Rio de Janeiro, Ed Relume Dumará, 1996.

Tinhorão, J. R., Tudo é música: samba se aprende na escola. Especial Quilombo, Rio de Janeiro, TVE, 1980 (Programa de TV)

Zaluar, A. Um debate disperso: violência e crime no Brasil da redemocratização. São Paulo Perspec. [online]. 1999, vol.13, n.3 [cited 2009-10-05], pp. 3-17.

. Integração Perversa: Pobreza e Tráfico de Drogas. Fundação Getúlio Vargas, Rio de Janeiro, 2004. 